\title{
ARTIGO BIBLIOGRÁFICO PODER E RESISTÊNCIA: UM ENSAIO SOBRE A DIMENSÃO CONCEITUAL DO “IMPÉRIO"
}

Marcio Goldman

\author{
Nesta vida, \\ pode-se aprender três coisas com uma criança: \\ estar sempre alegre, \\ nunca ficar inativo \\ e chorar com força por tudo o que se quer \\ (Paulo Leminski). \\ O spinozismo é o devir-criança do filósofo \\ (Gilles Deleuze e Félix Guattari, Mille Plateaux).
}

HARDT, Michael e NEGRI, Antonio. 2001. Império. Rio de Janeiro: Record. 501 pp.

Todos conhecemos grande livros que parecem nascer um pouco despercebidos, quase no silêncio, e que, por vezes e mais tarde, o tempo acaba revelando e fazendo falar. Mas existem também outros livros sobre os quais a ameaça que pesa não é a da indiferença imediata mas, bem ao contrário, a de um alarido tão estridente que torna quase surdos aqueles a quem ele deveria falar ${ }^{1}$.

Publicado originalmente em inglês no ano 2000, Império foi recebido com estardalhaço. Além das resenhas, críticas e seminários com que a academia costuma saudar trabalhos inovadores de fôlego, a mídia encarregou-se de ampliar o alcance da recepção por meio de entrevistas, debates e destaques. Algumas poucas informações talvez sejam interessantes, ainda que não se trate aqui de efetuar uma avaliação detalhada das repercussões do livro nem das recensões sobre ele - o que exigiria, creio, um trabalho à parte tal a quantidade e a má qualidade da esmagadora maioria dos trabalhos.

O leitor que digitar "'empire' + 'hardt' + 'negri' + 'review'" em algum instrumento de busca na Internet encontrará algo como 2.500 ocorrên- 
cias $^{2}$. Em 7 de julho de 2001, The New York Times dedicou ao livro uma resenha, assinada por Emily Eakin, que tratava Império como um acontecimento midiático e o anunciava como "the next big idea", insistindo que, para os autores, "Empire is good news". No Brasil, a repercussão na grande imprensa foi ainda mais rápida. Em 24 de setembro de 2000, o Caderno Mais da Folha de São Paulo dedicou dez páginas a Império, incluindo uma longa entrevista com Hardt e Negri e artigos de Zizek e do atual porta-voz da Presidência da República, André Singer. No dia 3 de outubro, Arnaldo Jabor anunciava, na Folha Ilustrada, o advento de um pensamento sobre a globalização oriundo de uma "nova esquerda". O Caderno de Idéias do Jornal do Brasil esperou até o lançamento da tradução brasileira para publicar uma extensa resenha de Peter Pál Pelbart. O livro foi objeto de uma sessão no Fórum Social Mundial de Porto Alegre em 2001 (mas esteve total e significativamente ausente em 2002), contando com a presença de Michael Hardt, que, além disso, participou de um debate no Rio de Janeiro organizado pelo jornal $O$ Globo ${ }^{3}$, bem como de um concorrido encontro na Universidade Federal do Rio de Janeiro.

Apresentado ora como um perigoso livro esquerdista, ora como uma alternativa de esquerda para o debate em torno da globalização, ora como o simples reconhecimento de que uma nova ordem mundial estaria definitivamente estabelecida, ora, ainda, como sinal de capitulação diante de um capitalismo pós-moderno triunfante, Império parece ter tido como destino ser tratado, em poucas palavras, como um fenômeno de moda, independente do caráter positivo ou negativo das avaliações.

Dever-se-ia reconhecer aqui, talvez, a contribuição do título do livro para esse tipo de tratamento particular. Mas deve-se reconhecer sobretudo que a obra nasceu em meio a uma série de eventos espetaculares, capazes de produzir interferências realmente poderosas em sua recepção. Escrito, como dizem os autores, em um período que conheceu as guerras do Golfo e do Kosovo (:17), o livro já publicado se deparou com nada menos do que o 11 de setembro de 2001 e com a subseqüente guerra do Afeganistão. O cuidado com que Hardt e, especialmente, Negri ${ }^{4}$ enfrentaram a questão não evitou nem que se tentasse utilizar Império para a análise do que estava acontecendo, nem que, do outro lado do espectro político, se denunciasse o livro como possuindo algum tipo de obscura conexão com o que passou a ser chamado de "terrorismo".

O fato é que se tanto barulho transformou o livro em um best-seller, também contribuiu para que inúmeras dimensões nele presentes - as essenciais creio - permanecessem quase ocultas. Além disso, é curioso 
observar que menos de três anos depois de sua publicação ele pareça ter "saído de moda", como se costuma dizer, expressão que revela bem o tipo de leitura dominante e, ao mesmo tempo, indica que talvez já se tenha hoje um certo recuo para uma apreciação um pouco mais aprofundada.

O alarido com que Império foi acolhido acabou, assim, por gerar uma série de mal-entendidos a respeito do livro, cada um deles envolvendo um certo número de desdobramentos e ameaçando ocultar os pontos efetivamente originais e centrais do trabalho. Eu sugeriria mesmo que o principal mal-entendido diz respeito exatamente à natureza do objeto abordado, envolvendo o próprio estatuto da noção que dá título ao livro. Mal-entendido que, por sua vez, parece ser o responsável por outros tantos contra-sensos incidindo sobre a noção de "multidão" (correlato de "Império", como veremos) bem como sobre o lugar concedido aos processos chamados de "globalização", "sistema mundial" ou "pós-modernidade" na economia geral da obra.

Se Império é relativamente claro em relação ao que se poderia denominar "contexto" da obra - se por isso entendemos o conjunto das questões: em quem e em que ela se inspira? Contra o que ela luta? A quem ela se dirige? - , creio que essa aparente clareza funciona igualmente como uma cortina de fumaça que também serve para ocultar as engrenagens da obra. Pois ela tem tudo para reforçar a falsa impressão de que o livro é o simples resultado de certas mudanças objetivas na ordem do mundo ou, na melhor das hipóteses, o produto do efeito dessas mudanças na subjetividade dos autores. O problema é que uma obra exige mais que processos objetivos ou reações subjetivas; exige que uma perturbação ou um mal-estar, sempre intersubjetivos, sejam elaborados tendo por destino espaços coletivos.

É nesse sentido que o mal-entendido acerca do que é efetivamente o "Império" de que falam Hardt e Negri é particularmente perturbador, assim como é significativo que praticamente nenhuma resenha ou apresentação do livro sequer mencione este ponto ${ }^{5}$. Com efeito, o que é "Império"?

Deve-se salientar que 'Império' é usado aqui não como metáfora, o que exigiria uma demonstração das semelhanças entre a ordem mundial de hoje e os Impérios de Roma, da China, das Américas, e assim por diante, mas como conceito, o que pede basicamente uma abordagem teórica (:14).

E em relação a um livro tão explicitamente inspirado no pensamento de Marx quanto Império, talvez valha a pena começar lembrando que 
já em 1975, ao escrever um pequeno trabalho sobre o Livro I de O capital, François Châtelet chamava a atenção para o fato de que Marx não estava tão interessado na determinação de causas quanto na descrição de estruturas, construídas por meio de "noções" ou conceitos elaborados de modo "materialista", ou seja, construtivista (Châtelet 1975:18-19, 35) ${ }^{6}$.

Quinze anos mais tarde, Deleuze e Guattari definiriam a filosofia justamente como "a arte de formar, de inventar, de fabricar conceitos" (Deleuze e Guattari 1991:8) ou "mais rigorosamente [...] a disciplina que consiste em criar conceitos" (:10). E os conceitos, prosseguem os autores, remetem necessariamente a "problemas": "os novos conceitos devem estar em relação com problemas que são os nossos, com nossa história e sobretudo com nossos devires" (:32). No entanto, afirmar que "Império" é um conceito, ou seja, que não é nem um dado empírico inerte nem uma metáfora, não significa dizer que a noção seja "ideal", pois não se trata de idealismo mas de construtivismo. Significa na verdade, na tradição que vai de Marx a Deleuze e Guattari, que o conceito de "Império" tem que ser construído, e que essa construção deve ser efetuada em função dos eventos históricos e "em função de problemas que se considera mal vistos ou mal colocados" (:22). Porque ainda que o conceito ocupe um plano distinto daquele das sensações ou das percepções, ele deve, não obstante, ser capaz de fazer perceber e sentir o mundo de outra forma.

Ora, a sensibilidade contemporânea parece ter se dividido, de alguns anos para cá, entre dois pólos: uma direita que se pretende nova e que nos repete que a modernidade foi superada (ou que deve ser implantada para poder ser superada), que o Estado-nação deixou de ser uma unidade fundamental, que o mundo se globalizou e, no limite, que a história acabou; e uma esquerda (que não sabe se se quer velha ou nova), que insiste na oposição entre o tradicional e o moderno, enfatiza o papel central do Estado, denuncia a globalização e a pós-modernidade como novos nomes para antigas formas de opressão e exploração, e acredita, no limite, que a história continua a mesma. É nesse sentido que a questão central de Império talvez seja a de nos tornar capazes de sentir e perceber o mundo de outra forma. Como fazê-lo? Construindo um conceito.

O próprio livro é dividido em quatro partes que correspondem claramente às etapas de construção do conceito de "Império". A primeira parte apresenta uma fenomenologia do Império; a segunda uma arqueologia; a terceira uma genealogia; e a quarta parte conclui com uma espécie de deontologia do Império. Entre as duas primeiras e as duas últimas intercala-se um Intermezzo que, como sustentam os autores, efetua a "mudança do reino das idéias para o da produção" (:17). E se é certamen- 
te verdadeiro que nem todas as partes apresentam a mesma qualidade (a descrição fenomenológica, por exemplo, parece muito superior à análise genealógica), é em seu conjunto que os cinco segmentos formulam uma verdadeira ontologia.

A primeira parte do livro inclui, também, uma seção onde os autores reconhecem explicitamente as três grandes influências teóricas que os teriam inspirado (:41-49): a obra de Michel Foucault, os trabalhos escritos em conjunto por Gilles Deleuze e Félix Guattari, uma série de pesquisas realizadas na Itália que receberam o nome de "operaísmo". Hardt e Negri apresentam, sucessivamente, cada uma dessas contribuições, reconhecem sua importância fundamental para o livro e, ao mesmo tempo, apontam seus limites e elaboram uma crítica: "nossa tarefa, por conseguinte, é desenvolver essas tentativas parcialmente bem-sucedidas" (:49).

De Foucault a idéia central a ser retida é a do "biopoder", ou seja, a de uma forma de poder que teria se constituído a partir do século XIX tomando a própria vida como objeto e que se caracteriza hoje por regular "a vida social por dentro, acompanhando-a, interpretando-a, absorvendo-a e a rearticulando" (:43). Ao mesmo tempo, lamenta-se a ausência de subjetividades criativas nas análises foucaultianas: "o que Foucault não entende, finalmente, é a dinâmica real da produção na sociedade biopolítica" (:47). Deleuze e Guattari teriam reconhecido essas subjetividades ao reintroduzirem o conceito de produção em suas análises, mas continuariam incapazes de determinar um conteúdo positivo para a promissora idéia de "produção desejante" (:47). Finalmente, o operaísmo teria encarado de frente a questão da produção ao restabelecer o vínculo entre produção e trabalho por meio do alargamento dessas noções nos conceitos de "trabalho imaterial" e "intelecto geral"; no entanto, sua incapacidade de inserir a produção no contexto biopolítico a não ser na forma de linguagem e comunicação continuaria a comprometer suas análises $(: 47-48)^{7}$.

É claro que poderíamos concordar, ao menos parcialmente, com essas críticas. Penso, não obstante, que, dos autores mencionados - ou melhor, das correntes de idéias e conceitos de que esses autores fazem parte Hardt e Negri extraiam mais, e outra coisa, do que aquilo que explicitamente admitem. Já o vimos no que diz respeito à concepção de filosofia como construção de conceitos, e o veremos em relação a outros pontos. Por ora, creio ser possível sustentar que, se quiséssemos ser muito sucintos e diretos, poderíamos dizer que a questão mais geral enfrentada por Império é a da transposição para o plano da análise política, histórica e etnográfica concreta de uma série de novas concepções acerca do poder 
elaboradas fundamentalmente ao longo das décadas de 60 e 70, concepções presentes em todas as influências reconhecidas por Hardt e Negri.

Deve-se observar igualmente que, além da explicitação de suas fontes teóricas, a parte "fenomenológica" de Império já inclui um esboço de elaboração da noção de "Império" como entidade conceitual, buscando definir desde o começo os quatro elementos constitutivos do conceito ${ }^{8}$ : ausência de fronteiras espaciais, ausência de limites temporais, exercício de um poder extensivo/intensivo, busca "uma paz perpétua e universal" (:14-15). Ora, é a confluência desses quatro elementos que permite definir uma nova forma de soberania, soberania que se torna imperial no mesmo sentido em que o mercado se torna global - ou seja, nem nacional nem internacional. O ponto central é que essa nova ordem imperial e global se encontra em processo de constituição, e é por isso que é inútil tentar opor aos argumentos de Hardt e Negri supostos exemplos empíricos de soberanias nacionais ainda se manifestando à plena força.

O problema está em outro lugar, a saber, na dificuldade de definição formal dessa nova ordem: em que poderia ela estar baseada e como poderia operar se as fronteiras nacionais não são mais seu limite e sua justificativa? A resposta é clara: a nova soberania imperial (assim como o mercado global) constitui-se em torno da noção de valores universais e opera por meio de um direito de polícia que se manifesta em situações sempre definidas como "de exceção". Não se invade mais um outro Estado após declarar guerra a ele alegando a necessidade de expansão de um espaço vital ou o direito de defesa das fronteiras. Na verdade, as guerras sequer chegam a ser declaradas e os ataques têm sempre sua justificativa em ameaças genéricas contra a "humanidade" como um todo e em violações de direitos e valores "universais" (:198-199).

Entretanto, essa fenomenologia, por mais acurada e impressionante que seja, deixa muito a desejar. Por um lado, não explica nem como nem por que essa nova forma de soberania se vem constituindo sob nossos olhos; por outro, parece insinuar uma certa onipotência daquilo que outrora se designava como "ideologia". A segunda parte de Império visa justamente ultrapassar essa perspectiva apenas fenomenológica. E ela o faz por meio de uma espécie de arqueologia da pós-modernidade, ou seja, da análise detalhada de um campo de dispersão ainda formal ou ideal, mas já tomado em sua dimensão de prática — prática discursiva, no caso ${ }^{9}$.

Aqui o centro do argumento é a idéia de que a modernidade se constitui, desde o Renascimento, como crise, e de que, na verdade, existiriam dois "modos" da modernidade. Isso porque esse termo compreende simultaneamente duas coisas bastante distintas ainda que interligadas: de um 
lado, a "descoberta do plano de imanência" (e não a simples recusa da transcendência como se costuma enfatizar), ou seja, a reterritorialização dos "poderes de criação" neste mundo; de outro, "modernidade" significa também a reação à descoberta desse plano de imanência. $O$ "aparelho transcendental" iluminista, as formulações da soberania moderna, a nação, o colonialismo, o imperialismo, o racismo, são, então, sucessivamente analisados como formas de reação e como tentativas de solucionar a chamada "crise da modernidade" — tentativas evidentemente vãs desde que se compreenda que a modernidade é ela mesma "crise" e que todas essas experiências são manifestações e sintomas desse caráter estruturalmente crítico da modernidade.

Porque na verdade o problema da modernidade é relativamente simples, ainda que de difícil, ou impossível, solução: como reintroduzir no campo de imanência algum princípio transcendente? Ou, em termos propriamente políticos, como comandar uma "multidão", quer dizer, um conjunto de singularidades que em última instância é quem detém todos os poderes? A teoria da representação é a resposta clássica da modernidade para o problema que a define: seja no campo dos saberes (tal qual analisado em Foucault 1966), seja no dos poderes (Foucault 1975). Problema simples, solução difícil: o controle imanente de um campo de imanência e uma estratégia de dominação que quase se confunde com aquilo que domina virão a ser as soluções para o problema, mas a modernidade do Iluminismo à Revolução Soviética — só será capaz de operar uma solução de compromisso, reintroduzindo uma transcendência (povo, classe etc.) no campo de imanência por meio dos artifícios do contrato, da representação ou da vanguarda.

A crise da modernidade, ou a modernidade como crise, consiste, então, simplesmente nesse conflito central e constitutivo entre o plano de imanência (a "multidão") e um princípio qualquer de transcendência. $O$ grande artífice dessa tentativa, por definição fracassada, de superação da crise, vem a ser o Estado, tendo em vista que apresenta sua existência como derivada de uma "nação" que, por sua vez, se enraizaria em um "povo" originário (:111-123). Na verdade, o Estado não passa do dispositivo que sobrecodifica a multidão em povo e em nação ${ }^{10}$.

A grande reviravolta ocorrida a partir de meados do século XX consistiu justamente na superação desse "paradigma da modernidade"11. E trata-se de fato de uma reviravolta, uma vez que a organização e o comando do campo de imanência constituído pela multidão deixam de ser pautados por qualquer tipo de transcendência e passam para o domínio da própria imanência. Da crise da modernidade, organizada em torno de 
um ou de poucos conflitos centrais, passa-se a uma espécie de "onicrise" da pós-modernidade, uma vez que a soberania imperial se organiza em "uma rede flexível de microconflitos" (:220-221; cf.: 209). As grandes divisões binárias e as exclusões que caracterizaram o exercício do poder moderno são progressivamente substituídas por "estratégias de inclusão diferenciada" (:213), e a "forma pós-moderna do racismo" é apenas um exemplo privilegiado desse "aparelho geral de comando do Império [que] consiste na realidade em três momentos distintos: um inclusivo, outro diferencial, e um terceiro gerencial" (:217 $)^{12}$.

Michel Foucault escreveu que "o Século XVIII sem dúvida inventou as liberdades" mas que, simultaneamente, "lhes forneceu um subsolo profundo e sólido - a sociedade disciplinar" (Foucault 1975:4a Capa). É exatamente disso que se trata aqui, mas o problema imperial consiste sobretudo em transportar os mecanismos disciplinares - criados, desenvolvidos e operados nos espaços fechados e limitados das fábricas, prisões, escolas e hospitais - para os espaços abertos e potencialmente sem limites do mundo como um todo. É à sociedade constituída, ou definida, por essa operação que Deleuze dá o nome de "sociedade de controle" e é nela que vivemos hoje em dia (Deleuze 1990) ${ }^{13}$

O último capítulo da segunda parte de Império começa, pois, a deslocar o foco da análise ao introduzir a questão dos mecanismos de poder e ao abandonar, depois do plano fenomenológico, aquele das práticas apenas discursivas. O anúncio dessa transição é efetuado no Intermezzo que, como dizem os autores, deve servir "para salientar a importância da mudança do reino das idéias para o da produção", funcionando "como uma dobradiça que articula o movimento de um ponto de vista para outro. Queremos que essa mudança de perspectiva funcione como o trecho de O capital em que Marx nos convida a abandonar a ruidosa esfera da troca para descer à morada oculta da produção" (:17).

É nesse sentido que a Parte 3 do livro aborda o que denominei acima uma "genealogia do Império", que talvez pudesse ser denominada, de forma mais simples, um esboço etnográfico e histórico da situação atual. A expansão imperialista ocidental (em relação à qual, é preciso sempre frisar, o modelo imperial representa um rompimento e não uma continuidade ou desenvolvimento) (:245-257); o New Deal e o tripé taylorismo (na linha de produção), fordismo (no regime salarial), keynesianismo (na macroeconomia), implantando um tipo de Estado que é, ao mesmo tempo, de bem-estar e disciplinar (:262-264); a II Guerra Mundial (com os conseqüentes Plano Marshall e os acordos de Bretton Woods) (:264-266); a descolonização (com a guerra do Vietnã como ponto ao mesmo tempo 
central e final) (:266-267); as novas relações econômicas e políticas internacionais (com as transnacionais e a globalização) (:267-274); o fim da União Soviética e do "socialismo real" (ele próprio resultado da falta de flexibilidade do modelo soviético, incapaz de efetuar a transição entre a soberania moderna e a pós-moderna) (:275, 297-300); esses são os pontos assinalados como chaves para a compreensão da passagem da antiga (ou "moderna") ordem social para a imperial (ou contemporânea).

Não deixa de ser verdade que a enumeração de todos esses acontecimentos apresenta um ar de superficialidade ou, pior, de trivialidade. $\mathrm{O}$ ponto fundamental, contudo, é que praticamente todos os eventos assinalados denotam não simples triunfos de um capitalismo preexistente ou de uma nova ordem já pronta e prestes a emergir. Na realidade, cada um desses acontecimentos envolve, de alguma forma, resistência e luta, e talvez a tese mais importante de Império seja exatamente a de que a nova ordem imperial se constitui a partir das reações contra as reações ao capitalismo ou à exploração econômica e política. Mas essa contra-reação imperial, ou a contra-reação que está dando origem ao Império, não procede por simples antagonismo e destruição de seus oponentes; ao contrário, ela incorpora, subordinando-os à sua própria lógica, elementos e forças que em sua origem a ela se opõem.

É nesse sentido que o fim do tripé taylorismo-fordismo-keynesianismo poderia ser lido como uma resposta às lutas operárias contra a exploração por ele representada (:288-289). Mas é nesse sentido também, e principalmente, que se poderia perceber que as características centrais da exploração capitalista contemporânea - envolvendo elementos como "mobilidade, flexibilidade, conhecimento, comunicação, cooperação, o afetivo" (:295) - resultam precisamente da captura das forças que ao longo das décadas de 60 e 70 as mobilizavam como gritos de protesto contra o capital e a dominação. Hoje, as mesmas palavras aparecem nos discursos de empresas e governos. "A experimentação 'meramente cultural' teve efeitos políticos e econômicos profundos" (:295), o que significa que é preciso aceitar que as origens do Império não podem ser localizadas apenas em transformações econômicas e políticas objetivas mas também, e talvez principalmente, na capacidade do capitalismo em incorporar as reações suscitadas por seu próprio modelo disciplinar, reações que trataram de inventar novas formas de existência e subjetividade, capturadas por sua vez por um capitalismo que se transforma de "disciplinar" em "de controle".

O percurso que conduz da fenomenologia do Império a uma ontologia da situação atual ${ }^{14}$, passando pela arqueologia do campo discursivo 
atual e pela genealogia de nossa contemporaneidade, permite, já no final da terceira parte do livro, esboçar o que seria essa ordem ontológica do presente. A "pirâmide da constituição global" (:330) seria formada por três camadas, cada uma delas composta por certos níveis. A primeira camada, mais estreita ou exclusiva, é ocupada basicamente pelos Estados Unidos da América, como única superpotência mundial, e por outros Estados-nação que, "atados entre si numa série de organismos - G7, os Clubes de Londres e de Paris, Davos, e assim por diante" (:331) —, são capazes de controlar os "instrumentos primários monetários globais" (:331). Em seguida, uma camada intermediária, ocupada pelas redes de empresas transnacionais e pelos Estados-nação que, através de certos órgãos, participam de tais redes. Finalmente, na base mais ampla da terceira camada teríamos o conjunto dos "representantes do povo": Estados-nação quando desempenham essa função uns perante os outros, "instâncias dos componentes tradicionais da sociedade civil, como a mídia e as instituições religiosas" (:333) e, principalmente, as chamadas organizações não-governamentais.

O que se denomina "Império" consiste, então, na justaposição articulada de todas essas instâncias. E mesmo observando repetidamente que "nosso Império pós-moderno não tem Roma" (:338), Hardt e Negri não se furtam a comparar a estrutura por eles exposta com aquela do Império Romano, tal qual desenhada no século II a.C. por um admirador grego, Políbio, que explicava o sucesso romano devido à sua capacidade em conjugar os poderes monárquico, aristocrático e democrático, anulando assim o contínuo movimento de ascensão e corrupção de cada um deles que caracterizaria a polis grega (:182-185, 335-337). Hoje, esses poderes estariam distribuídos, respectivamente, pelas três camadas que compõem a pirâmide imperial, e só estaríamos aguardando "a constituição imperial que vem aí" (:336) para assistir à reunião formal do poder monárquico dos Estados Unidos da América, com o aristocrático das grandes empresas e o democrático do povo. Duas observações são, contudo, essenciais aqui.

Em primeiro lugar, é apenas a reunião formal das três formas de poder que ainda não se completou integralmente já que, de um ponto de vista estritamente material, o "comando imperial" (:365) - assim como o mercado global (:168-169, 276) e o papel das ONGs como supostas representantes da multidão (:334-335) - já parece praticamente constituído, apoiado em "três meios globais e absolutos: a bomba, o dinheiro e o éter" (:366) — ou seja, o controle dos meios de destruição, de produção e de comunicação - , os quais, grosso modo, correspondem a ou funcionam sobre cada uma das camadas da pirâmide ${ }^{15}$. 
Em segundo lugar, não é inteiramente correto alocar cada uma dessas formas de poder a entidades como os Estados Unidos da América, as grandes empresas ou o povo. Pois a principal característica desses novos poderes é seu funcionamento "em rede", o que não exclui evidentemente que se concentrem ou se condensem em determinados pontos ou nós da malha. É nesse sentido, talvez, que se esclareça uma das críticas mais comuns dirigidas a Império, que diz respeito ao lugar ocupado pelos Estados Unidos no panorama desenhado pelo livro. Tornou-se mesmo algo banal se referir aos Estados Unidos como "Império" (no sentido em que se fala do "Império Romano"), mas é de outra coisa que falam Hardt e Negri, que, é claro, admitem que os Estados Unidos representam um espaço privilegiado na ordem imperial, sem querer dizer com isso que ocupem um lugar central. Ao contrário, são justamente certas peculiaridades da "constituição" norte-americana, no duplo sentido jurídico e material do termo, que explicam esse privilégio: por um lado, a Revolução Americana já teria definido a soberania como arranjo interno e imanente (ou seja, a partir de um modelo do poder em rede) (:179-180), não como representação e transcendência; por outro, a história norte-americana sempre se caracterizou por um expansionismo ilimitado, ou seja, por um movimento imperial que pressupõe espaços infinitos e fronteiras abertas, o que a diferenciaria do padrão imperialista europeu (:13-14, 185-186, 198-200, 406-407); finalmente, porque a história norte-americana recente teria sido o palco das principais resistências ao capitalismo disciplinar, resistências cuja incorporação - mais forte, talvez, nos Estados Unidos do que na Europa -, como vimos, estaria na origem do modelo imperial (:288-289, 295-297).

Da mesma forma, e talvez com evidência ainda maior, o poder econômico das grandes empresas funciona "em rede" e em profunda articulação com os Estados-nação e outras organizações (:331-332). Enfim, e este ponto é central, o poder "democrático" contemporâneo tampouco funciona na base da representação e da transcendência centralizada. Como vimos acima, o papel do Estado como representante de um "povo" e de uma "nação" correspondeu historicamente a um processo de sobrecodificação do plano de imanência revelado pelo primeiro modo da modernidade e a uma forma de tentar aí reintroduzir um princípio de transcendência.

Se a ontologia do Império traçada por Hardt e Negri é de fato aterrorizante, isso não significa, bem ao contrário, que ela seja necessariamente paralisante ou conformista. Como escreveu Michel Foucault (1981:182), "o otimismo não consiste em dizer que algo poderia ser melhor do que é, 
mas em reconhecer que tudo repousa sobre uma base frágil, contingente, arbitrária, histórica". Isso porque - e essa seria outra lição de Foucault uma filosofia do presente ou uma "ontologia histórica de nós mesmos" (Foucault 1984b:46-47) não podem dispensar a política e a ética. Desse ponto de vista, é imperativo reconhecer, em primeiro lugar, que os poderes quase absolutos do Império são inteiramente negativos: "sua eficácia é baseada na destruição (pela bomba), no julgamento (pelo dinheiro) e no medo (pela comunicação)" (:378). Em seguida, deveríamos aceitar o fato de que as antigas formas de resistência foram de algum modo absorvidas, o que não significa nem que tenham sido equivocadas ou inúteis, nem que a resistência seja impossível: "um novo tipo de resistência precisa ser inventado" (:329). Ou melhor, novos tipos de resistência já existem e sempre existiram, e a teoria das lutas contemporâneas, esboçada na primeira parte do livro (:61-84), tem justamente a função de demonstrar preliminarmente esse ponto. Finalmente, seria preciso seguir o Marx da Questão judaica e distinguir radicalmente entre a "emancipação" (que significa entrar no Império, de preferência em posição dominante) e a "libertação" (que significa livrar-se do Império, destruí-lo) (:385).

Mas quais seriam as condições desses movimentos? É aqui que o conceito de "multidão", tomado de Spinoza e devidamente reatualizado, vem desempenhar todo seu papel. É crucial, contudo, que não haja equívocos: como "Império", "multidão" também é um conceito (nem coisa em si, nem metáfora) e seus principais componentes são a singularidade e a multiplicidade. Se utilizássemos, então, o vocabulário de Michel Foucault, poderíamos dizer que a multidão é de ordem "microfísica"; se preferíssemos o de Deleuze e Guattari, diríamos que ela é "molecular".

Ora, isso significa que tanto as condições de controle da multidão (seja sob a forma da representação transcendente moderna, seja sob aquela do controle imanente pós-moderno) quanto aquelas de sua libertação remetem aos processos de corporificação, ou de "molarização", desses movimentos microfísicos ou moleculares. Basta que a multidão se segmente e se unifique como povo, nação e Estado para que tenhamos a soberania moderna em ação. E basta que essas entidades se dissolvam e a multidão se reagrupe, seguindo linhas de "identidades", para que outra forma de soberania, a imperial, se ponha em marcha — sem necessariamente fazer com que a outra desapareça, mas reconvertendo os segmentos por ela engendrados e sobrecodificados na forma da soberania pós-moderna.

Por outro lado, bastou aos movimentos da multidão se molarizarem como "proletariado" para que a soberania moderna fosse posta em xeque por mais de um século. Bastou que reagrupamentos "étnicos", "de gêne- 
ro", de "geração" se constituíssem para que a soberania, capturando-os, avançasse para outras formas. E bastaria que esses mesmos movimentos, traçando uma linha de fuga em relação a essas forças que continuamente deles se apropriam, produzissem outros recortes e outros coletivos para que novas lutas colocassem em questão os poderes da soberania imperial.

É por isso que as "duas cabeças" que formam o Império (a estrutura jurídica e biopolítica imperial, os "movimentos assistêmicos da multidão") (:78-79) são assimétricas, e que uma delas — o Império como forma possível de molarização da multidão - parece dominar a outra quando, na verdade, dela depende inteiramente. Mas é nessa direção também que a passagem histórica sugerida por Hardt e Negri (:71) entre o proletariado e a multidão como sujeitos das lutas deve ser entendida. O proletariado, na verdade, é uma das objetivações históricas possíveis da multidão, e o que assistimos hoje é a reorganização do "conjunto dos poderes para agir (ser, amar, transformar, criar) que reside na multidão" (:378-379), é sua busca por novas formas possíveis de objetivação e molarização.

A multidão não é, pois, uma massa indistinta e uniforme primeira, nem um conjunto de alteridades individualizadas e irredutíveis umas às outras: "a alteridade não é dada, é produzida" (:142). O que significa dizer não que o dado seja uma identidade primeira de base (o "povo" ou a "humanidade", por exemplo) que em seguida viria a sofrer processos de diferenciação, mas, bem ao contrário, que o modo de operação da modernidade é o de uma "máquina abstrata que produz identidades e alteridades" (:143) a partir de um fundo primeiro de singularidades e diferenças (a "multidão"), e que a pós-modernidade consiste simplesmente em uma tentativa de reorganizar esse campo de diferenciações e identificações ${ }^{16}$.

A multidão é o devir-criança da resistência e é nesse sentido que o conceito central de Império não é o de "Império" mas o de "multidão" justamente. E é apenas o apelo midiático do primeiro - aos quais os autores talvez, em um primeiro momento, não tenham sabido resistir — , bem como a facilidade com que se presta a interpretações mais fáceis e distorcidas, que poderiam, quem sabe, explicar aquele que, ao menos até agora, tem sido o estranho destino desse grande livro. 
Marcio Goldman é professor do PPGAS/Museu Nacional/UFRJ, pesquisador do CNPq e do Núcleo de Antropologia da Política (NuAP, Pronex), com projetos sobre política e eleições desenvolvidos em Ilhéus, sul da Bahia; é autor de Razão e diferença. Afetividade, racionalidade e relativismo no pensamento de Lévy-Bruhl (1994) e Alguma antropologia (1999).

\section{Notas}

1 Este ensaio resulta em grande parte do curso "Antropologia e Globalização (O Capitalismo Contemporâneo)", ministrado no 1o sem. de 2002 no PPGAS/ MN/UFRJ, em colaboração com Ana Cláudia Cruz da Silva. Além dela, Cecilia Mello, Célia Collet, Eugênia Motta, Juliana Jabor, Luciana Pereira, Ovídio Abreu Filho e Tomas Martin Ossowicki participaram, integral ou parcialmente, do curso. Meus agradecimentos a todos — assim como a Otávio Velho por algumas observações que infelizmente não pude incluir no texto. Mesmo assumindo todos os defeitos do ensaio, gostaria que seu caráter algo coletivo prestasse uma homenagem preliminar a um livro que exalta os poderes criativos do trabalho em conjunto e da multidão.

2 Uma amostra mais ou menos aleatória do que se encontra na Internet poderia ser:

http://eserver.org/clogic/3-1\&2/munck.html

http://struggle.ws/andrew/empirereview.html

http://webpages.ursinus.edu/rrichter/frmain04.htm

http://www.art.man.ac.uk/SPANISH/staff/Writings/empire.html

http://www.cpgb.org.uk/worker/420/empire.html

http://www.newcriterion.com/archive/20/oct01/empire.htm

http://www.newleftreview.net/NLR23909.shtml

http://www.tnr.com/100101/wolfe100101_print.html

http://www.zmag.org/Zmag/Articles/jan02gallagher.htm

http://www2.rz.hu-berlin.de/Content-TV/NewFiles/level2johnclarkbook reviews.html

3 Para uma idéia da repercussão de Império na Argentina, ver o interessante artigo de Beatriz Sarlo (2002:4, esp. nota 1). 
4 Se o assunto pode ser delicado para Michael Hardt - norte-americano, jovem e professor de literatura na Duke University —, ele é evidentemente complicadíssimo para Antonio Negri, que foi condenado por supostas atividades terroristas na década de 70, viveu no exílio na França durante quatorze anos e só retornou em 1997 à Itália para cumprir em regime semi-aberto os treze anos de prisão da única acusação que não foi retirada, "incitação à violência".

Observe-se, também, que a dinâmica editorial própria dos periódicos especializados faz com que este ensaio seja publicado quase dois anos após ser concebido e um ano após ser escrito. Nesse ínterim, a invasão do Iraque inspirou uma crítica aparentemente devastadora: o argumento central do livro teria sido desmentido pelos fatos históricos uma vez que a invasão teria correspondido a interesses exclusivamente norte-americanos. Embora este não seja o lugar para uma discussão histórica e etnográfica, eu lembraria o esforço para obter o apoio da ONU para a invasão, o fato de que mal ou bem uma "coligação" internacional foi construída e, finalmente e mais importante, o fato de que o Império não é um espaço desprovido de contradições e de que nestas os Estados-nação desempenham importantes funções.

5 A não ser para desqualificar a abordagem, como faz Roger Kimball (2001) em um artigo na Internet significativamente intitulado "The new anti-Americanism": "As palavras 'abordagem teórica' deveriam provocar um tremor na espinha de qualquer pessoa sensível [...]. Quando se trata de aplicar uma 'abordagem teórica' a um 'conceito', o resultado é: vale tudo".

6 Ver também Châtelet (1996:104): "O Capital não reflete nada, ele constrói".

7 Ver em especial: Foucault $(1975 ; 1976 ; 1984 a ; 1984 b ; 1997) ;$ Deleuze e Guattari (1972; 1980); Guattari (1977; 1989); Deleuze (1990) e Virno e Hardt (1996).

8 "Não há conceito simples. Todo conceito tem componentes, e se define por eles. Tem portanto uma cifra. É uma multiplicidade, embora nem toda multiplicidade seja conceitual" (Deleuze e Guattari 1991:21).

9 Definindo seu trabalho como uma "história das problematizações através das quais o ser se dá como podendo e devendo ser pensado, e das práticas a partir das quais essas problematizações se formam", Foucault (1984a:15) sustentava que a "dimensão arqueológica da análise permite analisar as próprias formas de problematização; a dimensão genealógica, sua formação a partir das práticas e de suas modificações".

10 "Pode ser verdade, como diz Benedict Anderson, que uma nação deva ser entendida como comunidade imaginada - mas aqui devemos reconhecer que a alegação aparece invertida, de modo que a nação passa a ser a única maneira de imaginar uma comunidade" (:124).

11 Hardt e Negri reconhecem a "pobreza" da noção de pós-modernidade: "mas ocasionalmente a preferimos às outras, porque pelo menos a pós-modernidade indica a notável mudança na História contemporânea" (:257). 
12 Essa concepção acerca da originalidade do racismo contemporâneo é claramente tomada de empréstimo a Deleuze e Guattari (1980:218): o racismo europeu não consiste em exclusões ou em atribuir a alguém o estatuto de Outro absoluto; ele procede por "determinação das variações de desvio, em função do rosto Homem branco [...]. Do ponto de vista do racismo, não existe exterior, não existem as pessoas de fora. Só existem pessoas que deveriam ser como nós, e cujo crime é não o serem".

${ }^{13}$ Escrevendo em 1990, Deleuze sugeriu que a análise foucaultiana da substituição das sociedades de soberania pelas sociedades disciplinares entre os séculos XVIII e XX deveria ser completada, hoje, pela análise da transição para as sociedades de controle, o que corresponderia à implantação de uma nova forma de capitalismo centrado mais na empresa que na fábrica, nos serviços e no marketing mais que na produção material, nas máquinas cibernéticas mais que nas mecânicas e na eliminação da necessidade do confinamento para garantir o controle (Deleuze 1990:240-242, 244-246).

14 "Ao longo da nossa argumentação, de modo geral lidamos com o Império nos termos de uma crítica do que é e do que existe e, por isso, em termos ontológicos" (:375).

15 Ou, como diz Negri, "O Império é a Constituição do mercado global. Naturalmente, quando se fala em Constituição, entendem-se duas coisas: o ordenamento jurídico e o comando. O comando imperial já está constituído, o ordenamento jurídico está em via de constituição" (Negri e Hardt 2000:4).

16 Observemos de passagem que é como engrenagem do dispositivo moderno de produção de identidades e alteridades (em sua variante colonial) que Hardt e Negri analisam, muito rapidamente, o lugar do que denominam "antropologia cultural" (:142-143). Seria fácil, é claro, demonstrar a superficialidade dessa posição. Mais interessante contudo, parece-me, é conceder a devida atenção ao movimento histórico que, no interior da própria antropologia, tem conduzido do infinito debate em torno dos universais e das diferenças, pensados como entidades mais ou menos substantivas, para a consideração dos microprocessos que envolvem singularizações, identificações e diferenciações. 


\section{Referências bibliográficas}

CHÂTELET, François. 1975. Le capital (Livre I). Paris: Hatier. . 1996. "Sobre os 'erros' de Marx". Textos Didáticos, 25:89-104 (O capital e outros estudos), Campinas: IFCH/ UNICAMP.

DELEUZE, Gilles. 1990. "Post-scriptum sur les sociétés de contrôle". In: Pourparlers. Paris: Minuit. pp. 240-247. e GUATTARI, Félix. 1972. L'AntiOEdipe. Paris: Minuit. . 1980. Mille plateaux. Paris: Minuit. .1991. Qu'est-ce que la philosophie? Paris: Minuit.

FOUCAULT, Michel. 1966. Les mots et les choses. Paris: Gallimard. .1975. Surveiller et punir. Naissance de la prison. Paris: Gallimard. . 1976. Histoire de la sexualité 1. La volonté de savoir. Paris: Gallimard. . 1981. "Les mailles du pouvoir". In: Dits et écrits (vol. IV). Paris: Gallimard. pp. 182-201.

.1984a. Histoire de la sexualité 2. L'usage des plaisirs. Paris: Gallimard.
_ . 1984b. "What is enlightenment?" In: P. Rabinow (org.), The Foucault reader. New York: Pantheon Books. pp. 32-50.

.1997. Il faut défendre la société. Paris: Gallimard/Seuil.

GUATTARI, Félix. 1977. La révolution moléculaire. Paris: Encres. .1989. Les trois écologies. Paris: Galilée.

KIMBALL, Roger. 2001. The new antiAmericanism (http://www.newcriterion.com/archive/20/oct01/empire. htm).

NEGRI, Antonio e HARDT, Michael. 2000. "A nova soberania (entrevista com Antonio Negri e Michael Hardt)" . Folha de S. Paulo, Caderno Mais, 24/ 9/2000:4-9.

SARLO, Beatriz. 2002. "Épica de la multitud o de la consolación por la filosofía". Punto de Vista, 73:4-9.

VIRNO, Paolo e HARDT, Michael. 1996. Radical thought in Italy. Minneapolis: University of Minnesota Press. 


\section{Resumo}

Este ensaio explora as dimensões propriamente conceituais de Império, de Michael Hardt e Antonio Negri. Tratase, basicamente, de levar a sério os autores quando afirmam que a noção não é nem uma metáfora nem uma descrição, mas um conceito. Vinculando essa afirmativa à perspectiva construtivista de Gilles Deleuze e Félix Guattari, procura-se demonstrar que o livro é uma tentativa de transpor para o plano da análise política, histórica e etnográfica concreta uma série de novas concepções acerca do poder elaboradas ao longo das décadas de 60 e 70. Nessa direção, busca-se demonstrar que o conceito de "Império" só é realmente operativo quando acompanhado de seu correlato, o de "multidão", o qual, assim como o primeiro, consiste em uma entidade conceitual que permite não apenas analisar o presente mas discernir linhas de ação nos espaços por ele desenhados. Palavras-chave Poder; Política; Identidade; Alteridade; Multidão; Império

\section{Abstract}

This essay explores the conceptual dimensions of Empire by Michael Hardt and Antonio Negri. In basic terms, it takes the authors seriously when they claim the notion is not a metaphor nor a description, but a concept. Linking this claim to the constructivist philosophy of Gilles Deleuze and Félix Guattari, it argues that the book is an attempt to transpose a series of new conceptions of power developed over the 1960s and 70 s onto the plane of concrete political, historical and ethnographic analysis. The essay also aims to show in the process that the concept of 'Empire' only really becomes operative when accompanied by its correlate 'multitude' like the former, a conceptual entity that not only enables us to analyze the present but also to discern lines of action in the spaces it traces.

Key words Power; Politics; Identity; Alterity; Multitude; Empire. 